\title{
МАШИНОСТРОЕНИЕ
}

УДК 621.777: 621.79

\section{ЭКСПЕРИМЕНТАЛЬНОЕ ИССЛЕДОВАНИЕ ВЛИЯНИЯ ПАРАМЕТРОВ ВОЛОКИ НА ТОЛЩИНУ ПОКРЫТИЯ}

\author{
А. Т. Бельский ${ }^{1}$, Н. В. Иноземцева ${ }^{2}$ \\ ${ }^{1}$ К. т. н., дочент кафедры «Механика» Гомельского государственного \\ технического университета им. П. О. Сухого, Гомель, Беларусь, e-mail: dmbat1@gstu.by \\ ${ }^{2}$ К. т. н., доцент кафредры «Механика» Гомельского государственного \\ технического университета им. П. О. Сухого, Гомель, Беларусь, e-mail: inozem-nata@gstu.by
}

\begin{abstract}
Ресрерат
Представлена конструкция узла волочения, разработанная авторами, для формирования защитных покрытий и приводятся результаты экспериментальных исследований влияния параметров волочильного инструмента с целью выработки практических рекомендаций по созданию оптимальных условий нанесения покрытий.
\end{abstract}

Ключевые слова: волочение, волока, толщина покрытия, металлический порошок, проволока.

\section{EXPERIMENTAL STUDY OF THE INFLUENCE OF DIE PARAMETERS ON COATING THICKNESS}

\section{Abstract}

\section{A. T. Belsky, N. V. Inozemtseva}

It is presented design of the drawing unit, developed by the authors, for the formation of protective coatings, and the results of experimental studies of the influence of drawing tool parameters are given in order to develop practical recommendations for creating optimal coating application conditions.

Keywords: volochenie, voloka, tolshchina pokrytiya, metallicheskij poroshok, provoloka.

\section{Введение}

Способы нанесения металлических порошковых покрытий на металлическую основу в технологиях плакирования методом совместной пластической деформации основы и порошка покрытия отличаются высокопроизводительностью и обеспечивают получение слоистых материалов. Совместная пластическая деформация реализуется с помощью операций обработки металлов давлением, таких как обратное выдавливание, прокатка и волочение. Из анализа существующих гипотез соединения металлов в твердом состоянии можно прийти к выводу, что для протекания процесса схватывания необходимо сблизить контактируемые поверхности на расстояния соизмеримые с параметрами кристаллической решетки, увеличить активность частиц кристаллической решетки путем давления и увеличения температуры, а также создать условия для протекания пластической деформации в зоне контакта. Все эти условия имеют место при формировании покрытия из металлического порошка на проволоке в процессе ее волочения.

Следует отметить, что для металлического порошка характерной особенностью является наличие огромной поверхности по отношению к объему. В связи С этим для металлических порошков проявление схватывания является значительным, так как сила сцепления прямо пропорциональна площади контактов. По мере повышения давления контактная поверхность между частицами порошка возрастает, атомы сближаются и их взаимодействие проявляется в виде сцепления [1]. При формировании покрытия из металлического порошка на длинномерном изделии в процессе его волочения происходит увеличения площадей боковых поверхностей контактируемых тел, что способствует разрушению окисных пленок, появлению ювенильных поверхностей и протеканию процесса соединения металлов в твердом состоянии. Увеличение активности атомов кристаллической решетки при нанесении покрытия из металлического порошка в процессе волочения проволоки происходит также благодаря повышению температуры в зоне контакта, так как вся работа деформации и работа сил трения превращается в тепло.

При формировании покрытия в процессе волочения на протяжении всей зоны уплотнения и деформации наблюдается пластическая деформация частиц металлического порошка. В начальный момент увеличение плотности формируемого покрытия осуществляется в основном за счет межчастичного сдвига металлического порошка [2] Доля пластической десрормации в уплотнении на этом этапе мала. Однако при достижении состояния плотности утряски дальнейшее уплотнение металлического порошка осуществляется в основном за счет пластической деформации его частиц, что приводит к схватыванию отдельных частиц металлического порошка друг с другом в зоне их контакта. При достижении в материале сердечника напряженного состояния, когда интенсивность напряжений будет равна пределу текучести его материала, начинается также пластическая деформация и проволоки. При этом происходит схватывания между частицами порошка и протягиваемым изделием и образуется покрытие.

Целью данной работы является определение влияния основных параметров волочения на толщину покрытия.

Проволока является одним из массовых продуктов метизного производства. Исследование покрытий на проволоке позволяет значительно расширить область применения проволоки, увеличить срок службы и повысить качество. Толщина защитного покрытия является основным параметром, характеризующим качество получаемой проволоки, так как при увеличении толщины защитного покрытия наблюдается уменьшение адгезии, а при увеличении толщины имеем увеличение неоднородных явлений в покрытии [3].

Оборудование, материалы и методика исследования

Одним из условий формирования покрытия на длинномерном изделии из металлического порошка является обеспечение поступления его в рабочий конус волоки.

В связи с этим была разработана конструкция узла волочения для формирования покрытия, которая изображении на рис. 1.

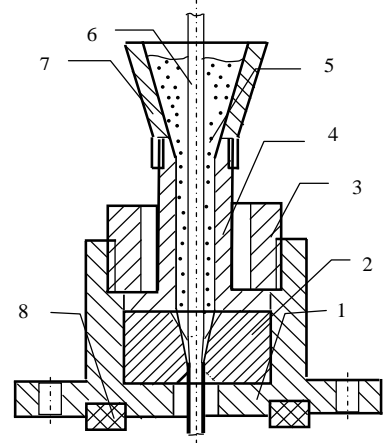

Рисунок 1 - Схема узла формирования покрытия из металлического порошка 
Вестник Брестского государственного технического университета. 2021

Узел формирования покрытия из металлического порошка состоит из фланца 1, внутри которого расположен волочильный инструмент 2. К нему с помощью гайки 3 прижимается напорная трубка 4. Для улучшения поступления порошка металла покрытия 5 в зазор между напорной трубкой 4 и покрываемым длинномерным изделием 6 с помощью резьбы крепили воронку 7.
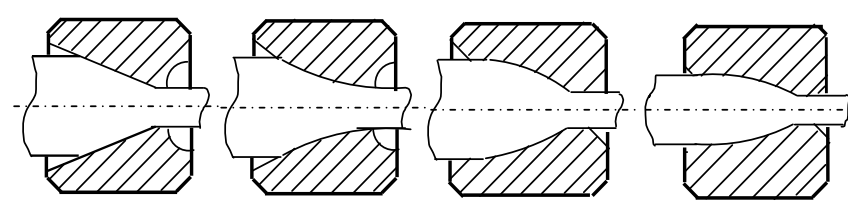

a) б)

B)

г)

а) коническая; б) радиально выпуклая;

в) радиально вогнутая; г) сигмоидальная

Рисунок 2 - Формы рабочей зоны волоки

С целью использования узла формирования покрытия при нанесении покрытия из металлического порошка в вакуумной камере, на опорной поверхности фланце 1 выполнялся кольцевой паз, в котором размещалось кольцо 8 из вакуумной резины.

К волочильному инструменту относятся волоки, которые могут иметь одну из следующих форм рабочей зоны (рис. 2): коническую, радиальную выпуклую, радиальную вогнутую и сигмоидальную форму.

Изучая литературные источники по применению волок с различными формами зоны деформации [4], можно сделать следующие выводы:

1) при применении волоки с радиальной выпуклой формой рабочей зоны наблюдается увеличение отгона смазочного материала изза увеличения угла у входа;

2) у волоки, имеющей радиальную вогнутую форму рабочей зоны, наблюдается увеличения воздействия сил трения на стенки канала, что приводит к его быстрому изнашиванию;

3) волока с сигмоидальной формой рабочей зоны не имеет существенных преимуществ по сравнению с волоками других профилей, а также возникают трудности при ее изготовлении;

4) наибольшее распространение при волочении проволоки получили волоки с конической формой рабочей зоны.

Поэтому для формирования покрытий из металлического порошка на проволоке в процессе ее волочения была выбрана волока с конической формой рабочей зоны.

Согласно [5] канал волоки (рис. 3) в направлении волочения делится на четыре зоны: входная зона 1, рабочая зона 2, калибрующая зона 3 и выходная зона 4.

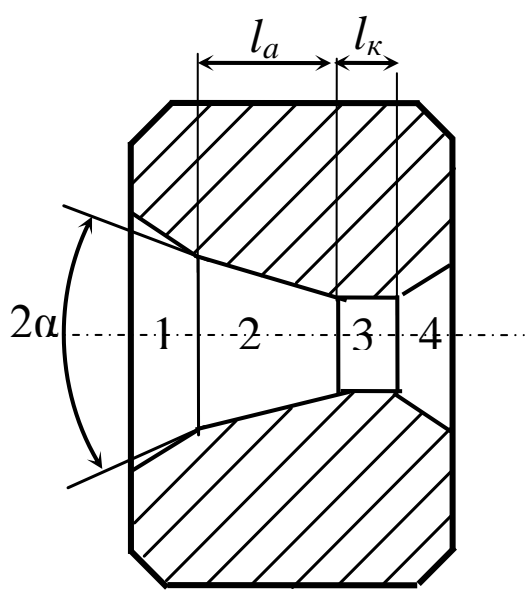

Рисунок 3 - Зоны волоки

Анализируя назначения этих зон, можно придти к выводу, что наличие входной зоны приводит к улучшению условий подачи по рошка в зону деформации. Выходная зона защищает нанесенное покрытие на проволоке от царапин, которые могут образоваться от трения о кромки канала. Калибрующая зона придает полученному изделию заданные поперечные условия.

Таким образом, существенное влияние на процесс формирования покрытия из металлического порошка на проволоке будет оказывать рабочая зона волоки.

В связи с этим проводились эксперименты по изучению влияния параметров рабочей зоны волоки на толщину и свойства формируемых порошковых покрытий на проволоке. Для проведения были изготовлены волоки из стали Х12, которые имели различные значения углов рабочей зоны и ее длины. Выходная зона имела коническую форму.

\section{Материалы}

Из анализа литературных источников [5] можно сделать вывод, что наибольшее применение в качестве материалов покрытия длинномерных изделий нашли такие металлы, как олово и свинец.

Покрытия из свинца и олова медной проволоки значительно повышает ряд ее эксплуатационных характеристик. Поэтому для проведения экспериментов с целью определения оптимальных параметров узла формирования покрытия, осуществляли нанесение покрытий из олова и свинца на медную проволоку марки М1, химический состав которой регламентирует ГОСТ 859-78 [6].

Химический состав свинцового порошка марки ПС2 ГОСТ 16138-78 [7] приведен в табл. 1.

Таблица 1 - Химический состав свинцового порошка марки ПС2
\begin{tabular}{|c|c|c|c|c|c|c|}
\hline $\begin{array}{c}\text { Массовая } \\
\text { доля } \\
\text { свинца, } \%\end{array}$ & $\mathrm{Fe}$ & $\mathrm{Cu}$ & $\mathrm{Sb}$ & $\mathrm{As}$ & $\mathrm{Bi}$ & 0 \\
\cline { 2 - 7 } & 0,001 & 0,001 & 0,0005 & 0,005 & 0,005 & 0,2 \\
\hline 99,7 &
\end{tabular}

Свинцовый порошок марки ПС2 представляет собой мелкодисперсный порошок свинца. Его гранулометрический состав представлен в табл. 2

Таблица 2 - Гранулометрический состав свинцового порошка марки ПС2

\begin{tabular}{|c|c|c|c|}
\hline \multirow{2}{*}{ Марка } & Прохождение через сито с сетками номер, \% \\
\cline { 2 - 4 } & 025 & 02 & 0045 \\
\hline ПС2 & 99 & 97 & - \\
\hline
\end{tabular}

Химический состав оловянного порошка марки ПО2 ГОСТ 9723-73 [7] приведен в табл. 3

Таблица 3 - Химический состав оловянного порошка марки ПО2

\begin{tabular}{|c|c|c|c|c|c|c|c|c|}
\hline \multirow{2}{*}{$\begin{array}{c}\text { Массовая } \\
\text { доля } \\
\text { олова, } \%\end{array}$} & \multicolumn{7}{|c|}{ Массовая доля примесей, \% } \\
\cline { 2 - 10 } & $\mathrm{Pb}$ & $\mathrm{Fe}$ & $\mathrm{Cu}$ & $\mathrm{S}$ & $\mathrm{Bi}$ & $\mathrm{As}$ & $\mathrm{Sb}$ & $\mathrm{O}$ \\
\hline 99,0 & 0,25 & 0,02 & 0,03 & 0,016 & 0,05 & 0,015 & 0,05 & 0,05 \\
\hline
\end{tabular}

Гранулометрический состав оловянного порошка марки ПО2 аналогичен гранулометрическому составу свинцово порошка марки ПС2.

\section{Определение толщины покрытия}

В качестве критерия для оптимизации параметров узла волочения, применяемого для формирования покрытия из металлического порошка на длинномерном изделии, была выбрана толщина покрытия.

Существующие методы измерения толщины покрытия постоянно совершенствуются, а область их применения расширяется. Все существующие методы нанесения покрытий можно разделить на два вида: неразрушающие и разрушающие методы.

К неразрушающим методам контроля относятся: радиометрические, магнитные, электрические.

К разрушающим методам контроля относятся: металлографический, метод измерения индикатором часового типа, метод взвешивания, метод электролитического послойного травления, кулонометрический, 
химические, метод измерения напряжения пробоя, метод вдавливания и другие.

Рассматривая возможности применения того или иного метода остановились на металлографическом методе. Применение этого метода дает возможность не только определять толщину покрытия, но и получить дополнительные данные о качестве нанесенного покрытия, например измерять микротвердость покрытия, изучать его равномерность по контуру.

Измерение толщины покрытия производили на поперечных микрошлифах с помощью металлографического микроскопа ММУ-3.

Для изготовления микрошлифов образец с покрытием помещался пустотелый цилиндр и закреплялся в нем с помощью эпоксидной смолы с отвердителем. После затвердевания осуществляли шлифования на шлифовальных кругах.

\section{Экспериментальная часть}

Для исследования параметров рабочей зоны волоки на толщину формируемого покрытия из металлических порошков осуществляли волочения проволоки, исходный диаметр которой был равен $d$ диаметру калибрирующей зоны волоки $d_{k}$.

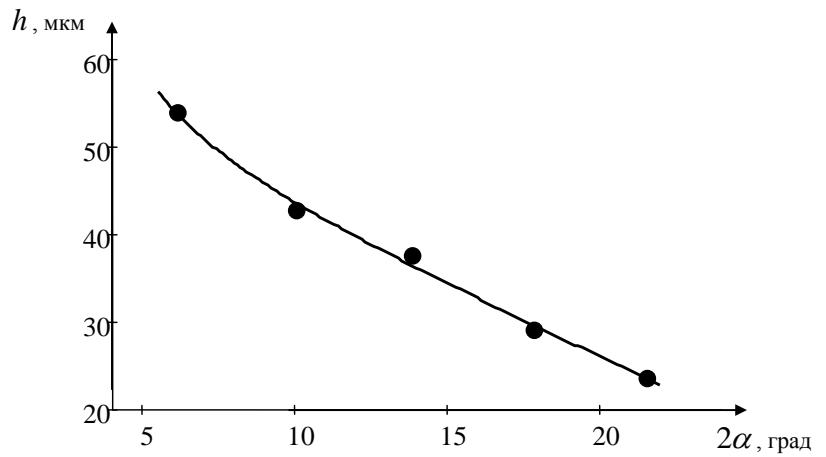

Рисунок 4 - Зависимость толщины оловянного покрытия на медной проволоке от угла рабочей зоны волоки

Для проведения экспериментов по определению влияния угла рабочей зоны волоки были изготовлены две партия волок, у которых при постоянной длине рабочей зоны $l_{\alpha}$ изменяли ее угол $2 \alpha$. Первая партия характеризовалась тем, что диаметр калибрующей зоны волок был равен $d_{\kappa}=3,8$ мм, а во второй партии этот диаметр был увеличен до $d_{k}=5,0$ мм.

При формировании покрытия из порошка олова марки ПО2 на медную проволоку марки М1 с применением первой партии волок после замеров его толщины были получены результаты, которые представлены на рис. 4. При проведении экспериментов скорость волочения была постоянной и была равна $V=0,074$ м/с.

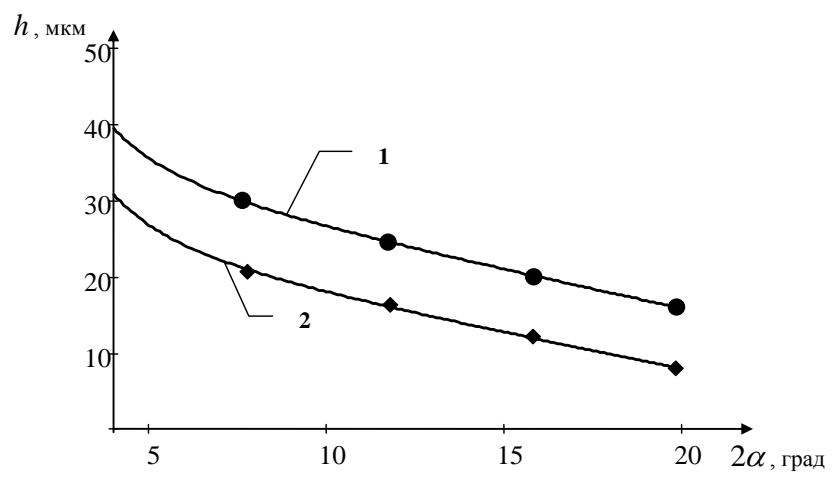

Рисунок 5 - Зависимость толщины оловянного покрытия на медной проволоке от угла рабочей зоны волоки $1-V=0,03 \mathrm{~m} / \mathrm{c} ; 2-V=0,134 \mathrm{~m} / \mathrm{c}$

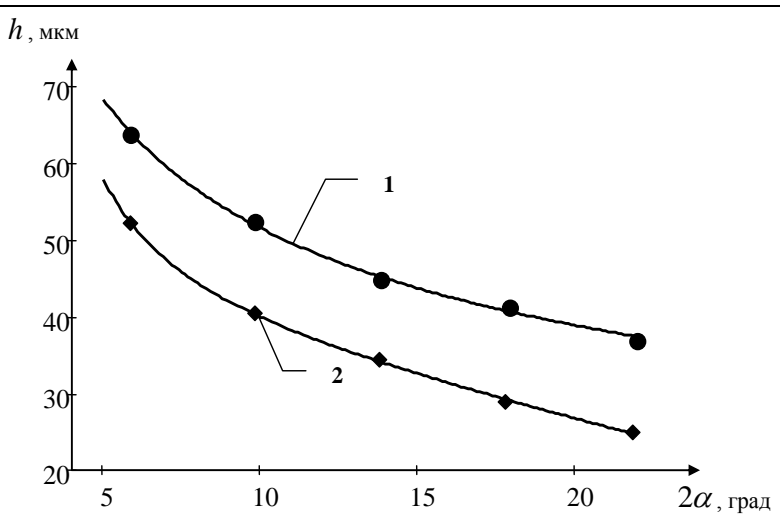

Рисунок 6 - Зависимость толщины свинцового покрытия на медной проволоке от угла рабочей зоны волоки $1-V=0,116 \mathrm{~m} / \mathrm{c} ; 2-V=0,209 \mathrm{~m} / \mathrm{c}$

При использовании волочильного инструмента второй партии с диаметром калибрующей зоны волоки $d_{\mathrm{k}}=5$ мм нанесение покрытий осуществляли при различных скоростях волочения. Углы рабочей зоны волоки в этом случае изменялись от $2 \alpha=4^{0}$ до $2 \alpha=20^{\circ}$. После обработки экспериментальных данных были получены результаты, которые представлены на рис. 5.

Как и при использовании волочильного инструмента первой партии, характер изменения толщины покрытия в зависимости от угла рабочей зоны волоки, несмотря на увеличение исходного диаметра проволоки, остается прежним, а изменение скорости волочения также приводит к уменьшению толщины покрытия.

Формирование свинцового покрытия на медную проволоку из порошка свинца марки ПС2 с применением первой партии волок осуществляли также при различных скоростях волочения. Обрабатывая экспериментальные данные, были получены зависимости, представленные на рис. 6. Характер изменения толщины свинцового покрытия от угла рабочей зоны волоки аналогичен изменению толщины оловянного покрытия.

Для изучения влияния длины $l_{a}$ рабочей зоны волоки на толщину покрытия, наносимого в процессе волочения проволоки, были изготовлены волоки с различными длинами рабочей зоны (рис. 7), которая изменялась от $I_{a}=4,5$ мм до $I_{a}=14,5$ мм, при постоянном угле рабочей зоны волоки.
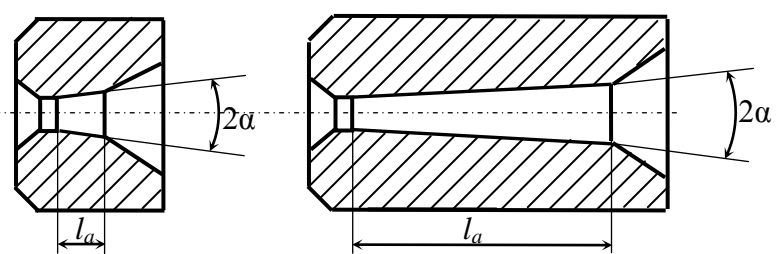

Рисунок 7 - Волочильный инструмент с различной длиной рабочей зоны

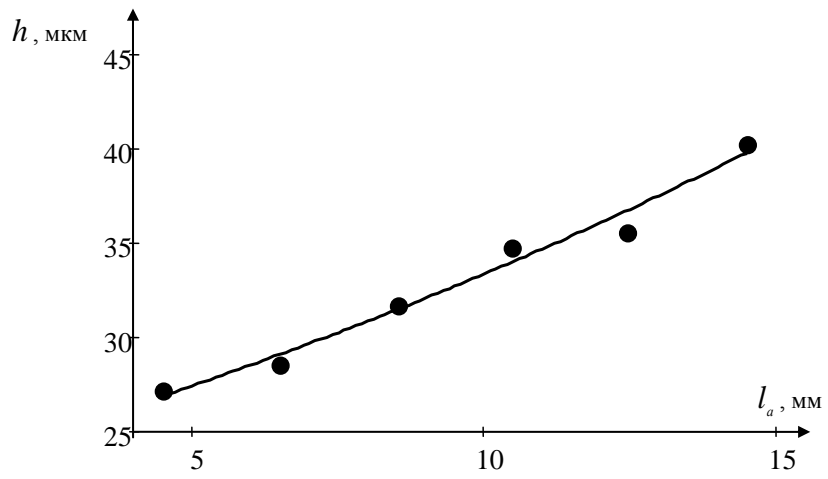

Рисунок 8 - Зависимость толщины покрытия на медной проволоке от длины рабочей зоны волоки 
Вестник Брестского государственного технического университета. 2021

Формирование покрытий происходило при постоянной скорости волочении медной проволок с использованием оловянного порошка. Обрабатывая результаты экспериментальных данных, была получена зависимость изменения толщины покрытия на медной проволоке, которая представлена на рис. 8.

Из приведенных зависимостей следует, что увеличение толщины формируемого покрытия из порошка олова наблюдается с увеличением длины рабочей зоны волоки.

\section{Заключение}

На основании проведенных экспериментов следует, что толщина покрытия формируемого покрытия уменьшается с увеличением угла рабочей зоны волоки, а также скорости волочения проволоки.

Применение волочильного инструмента с удлиненной рабочей зоной приводит к увеличению толщины покрытия.

\section{Список цитированных источников}

1. Павлов, Н. Н. Прессование и прокатка металлических порошков Н. Н. Павлов. - Л. : ЛПИ, 1980. - 64 с.

2. Драйвер, В. О пластической деформации частиц / В. Драйвер, Н. Н. Павлов // Проблемы порошковой металлургии: Материаль Всесоюзной конференции, посвященной 200-летию со дня рождения основателя порошковой металлургии П. Г. Соболевского. Л. : Наука, 1982. - С. $85-87$

3. Андрианов, Н. В. Адгезия резины к металлокорду и ее сохранение Н. В. Андрианов, А. Н. Савенок, А. А. Кравцов, А. А. Леднева // Литье и металлургия: научно-практический журнал. - 2005. № 2(34). - С. 36-44.

4. Исследование численным моделированием влияния формы деформирующей зоны волоки при волочении стальной высокоуглеродистой проволоки на температурное и напряженно-десоормированное состояние в проволоке и волоке / Ю. Л. Бобарикин [и др.] // Литье и металлургия: научно-практический журнал. - 2012. №3(67). - C. 196-200.
5. Перлин, И. Л. Теория волочения / И. Л. Перлин, М. 3. Ерманок. М. : Металлургия, 1971. - 448 с.

6. Медь. Марки: ГОСТ 859-2014. - М.: Стандартинформ, 2015. - 8 с.

7. Порошок свинцовый. Технические условия: ГОСТ 16138-1978. М. : Изд-во стандартов, 1978. - 9 с.

8. Порошок оловянный: ГОСТ 9223-1977. - М. : Изд-во стандартов, 1977. $-11 \mathrm{c}$

\section{References}

1. Pavlov, N. N. Pressovanie i prokatka metallicheskih poroshkov / N. N. Pavlov. - L. : LPI, 1980. - 64 s.

2. Drajver, V. O plasticheskoj deformacii chastic / V. Drajver, N. N. Pavlov /I Problemy poroshkovoj metallurgii: Materialy Vsesoyuznoj konferencii, posvyashchennoj 200-letiyu so dnya rozhdeniya osnovatelya poroshkovoj metallurgii P. G. Sobolevskogo. - L. : Nauka, 1982. - S. 85-87.

3. Andrianov, N. V. Adgeziya reziny k metallokordu i ee sohranenie / N. V. Andrianov, A. N. Savenok, A. A. Kravcov, A. A. Ledneva // Lit'e i metallurgiya: nauchno-prakticheskij zhurnal. - 2005. - № 2(34). S. 36-44.

4. Issledovanie chislennym modelirovaniem vliyaniya formy deformiruyushchej zony voloki pri volochenii stal'noj vysokouglerodistoj provoloki na temperaturnoe i napryazhenno-deformiro $\urcorner$ vannoe sostoyanie v provoloke i voloke / YU. L. Bobarikin [i dr.] // Lit'e i metallurgiya: nauchno-prakticheskij zhurnal. - 2012. - №3(67). - S. 196-200.

5. Perlin, I. L. Teoriya volocheniya / I. L. Perlin, M. Z. Ermanok. - M. : Metallurgiya, 1971. - $448 \mathrm{~s}$.

6. Med'. Marki: GOST 859-2014. - M.: Standartinform, 2015. - $8 \mathrm{~s}$.

7. Poroshok svincovyj. Tekhnicheskie usloviya: GOST 16138-1978. M. : Izd-vo standartov, 1978. $-9 \mathrm{~s}$.

8. Poroshok olovyannyj: GOST 9223-1977. - M. : Izd-vo standartov, 1977. $-11 \mathrm{~s}$.

Материал поступил в редакцию 22.04.2021 